\title{
The Influence of Schedules of Open Office Occupants' Presence on Building's Energy Demand
}

\author{
Jonas Bielskus*, Violeta Motuzienė \\ Department of Building Energetics, Faculty of Environmental Engineering, \\ Vilnius Gediminas Technical University, Vilnius, Lithuania
}

Received 4 February 2020; accepted 31 March 2020

\begin{abstract}
Many studies show, that there is a difference between actual and design energy consumption in energy efficient and sustainable buildings. As a rule, buildings consume more energy than it has been foreseen at the design stage. Occupants' behaviour in buildings is also identified as one of the main reasons causing the so called Performance Gap. Having mobile workstations, opened plan offices are becoming more popular in design solutions in sustainable buildings. Here we have studied one of such office spaces. Monitoring of real occupancy was performed and real occupation schedules were statistically generated. The schedules were compared to the ones given by European Standard for energy performance calculation as well as with default schedules proposed by simulation software DesignBuilder. The comparison shows a significantly lower measured occupancy compared to the above-mentioned schedules. To compare the influence of occupancy related assumptions on predicted energy demand, DesignBuilder model was created and simulated for 3 different occupancy schedules. The results have shown that primary energy demand of a building due to assumptions related with an occupancy, compared to default DesignBuilder schedules are: $111 \mathrm{kWh} / \mathrm{m}^{2}(32 \%)$ higher than the standard case and $152 \mathrm{kWh} / \mathrm{m}^{2}(44 \%)$ than the actual one.
\end{abstract}

Keywords: passive occupants' behaviour, open plan office, schedules, Performance Gap, energy simulation.

\section{Introduction}

Despite the fact that a growing number of countries have been launching new policies in improving the building energy performance, the average energy consumption per person in the global buildings sector has practically been unchanged since 1990 (Yan et al., 2017). The energy efficiency and decarbonisation policy leads to a growing number of energy efficient and sustainable buildings, causing energy requirements for heating in buildings approaching zero. Ventilation, cooling and DHW systems, which are strongly dependant on building users and their behavioural features, are becoming dominant energy-using systems in the building.

According to the IEA (International Energy Agency), in the Energy Buildings and Communities Program, Annex 53 (Yan et al., 2017) - energy consumption in buildings is determined by six parameters: climate, building envelope and its thermal properties, building interior equipment and energy systems, interior design criteria, building operation and maintenance as well as the behaviour of occupants indoors. Occupants can influence the energy consumption of the building passively - simply by their presence in the building (emitting heat) and actively (by action) - adjusting indoor climate systems, using electrical appliances, adjusting shading, opening windows, using hot water, etc. By active actions, occupants are consciously or unconsciously seeking to improve their well-being. Occupants' behaviour in the building is influenced by a variety of factors, such as personal characteristics and well-being, outdoor weather conditions, indoor microclimate, etc. According to Delzendeha et al. (2017) and Hong et al. (2016), the following factors determine and should be monitored in relation to the energy related behaviour of a building (Delzendeha et al., 2017) and (Hong et al., 2016):

1. Climate: outdoor weather conditions - temperature, humidity, precipitation, wind, solar radiation, contamination, etc.

2. Policy and regulation - energy saving measures adopted by state politicians and their regulations.

3. Architecture and structural elements.

4. Human well-being, personal well-being, illness, emotional state, etc.

5. Social Factors - experiences gained from belonging to a particular social group, family or elsewhere.

6. Economic factors - the financial position of occupants.

${ }^{*}$ Corresponding author. E-mail: jonas.bielskus@vgtu.lt 
The main goal of this study is to define the dependence of predicted energy demand, simulated with DesignBuilder, on the assumptions related to presence of occupants indoors in opened space office.

\section{The object of research}

For the actual occupancy profiles research, a building with open offices and mobile workstations (employees do not have their own tables, they occupy the one, which is not occupied when they arrive) was selected. The building is energy efficient and sustainable - LEED certified, which assumes that it provides better working conditions for the users. Basic data related to the building are presented in Table 1.

Table 1. General data of the building

\begin{tabular}{|c|c|}
\hline & Object \\
\hline Purpose & Office \\
\hline Construction work & 2017 \\
\hline Number of floors & 9 \\
\hline Useful area & $22164 \mathrm{~m}^{2}$ \\
\hline Energy efficiency label & B \\
\hline Certificate of sustainability & LEED \\
\hline
\end{tabular}

The comfort in the building during the heating season is maintained by radiators' system. During the cooling season - by with active (combined with ventilation) chilled beams. The temperature in the room both for heating or cooling is adjusted by thermostats installed $2.5 \mathrm{~m}$ above the floor. Thermostats are centrally controlled from the main control system (BMS - Building Management System), so occupants have no possibility to adjust the indoor climate. Fresh air is supplied to the premises through active chilled beams and the air flow is constant during the occupied hours. Ventilation and cooling systems are turned on from 6:30 a.m. to 7:00 p.m. Heating system is always turned on during the heating season.

\section{Methodology}

The research consists of two parts: experimental - measurement of real occupancy and analytical simulations.

\section{Experimental}

One of the most important measurement parameters in the study is the occupation of people, which influences changes in energy consumption of indoor climate systems. Indoor occupancy or workplace occupancy can be accomplished with devices, one of which is 3D depth cameras, which have been extensively studied by Diraco (Diraco et al., 2015). 3D cameras can determine people's presence and behaviour with great accuracy. Another method investigated by Heidmann Pedersen is PIR (Passive infrared sensor) and noise sensors based or VOC (volatile organic compounds), $\mathrm{CO}_{2}$ (carbon dioxide), relative humidity, but they only detect the presence / absence of people indoors

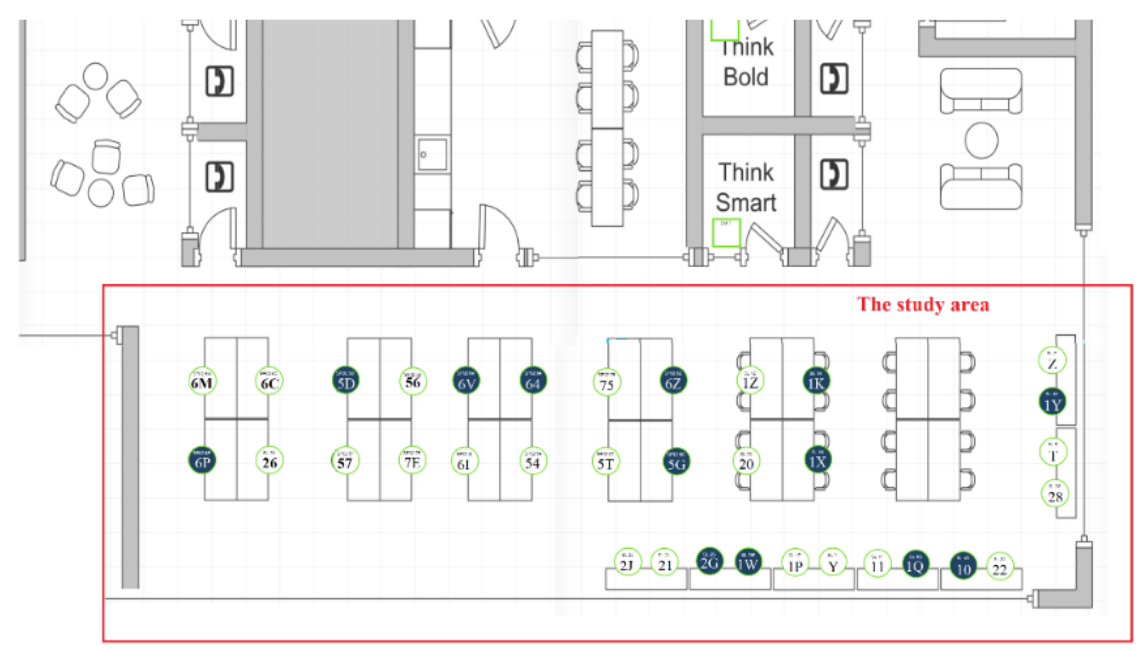

Figure 1. Monitored human occupancy room plan with PIR sensor locations 
(Pedersen et al., 2017). $\mathrm{CO}_{2}$, VOC, $\mathrm{HR}$ (relative humidity) are sensors that record increase of the measured parameters compared to normal parameters, thus detecting the presence of people in the room. This is not an accurate method of measuring people's occupancy because they indicate that the room is occupied and they do not state the exact number of occupants.

The object of the research is a functioning office in Vilnius. In one of the rental premises, PIR motion detectors were installed at each workstation under the table (see Figure 1). Real measurements were performed for the period from $08 / 09 / 2019$ to $12 / 12 / 2011$ and there were 32 observed workstations in the area. Therefore, it was possible to accurately determine the exact number of people in the room at any time during working hours and their variation over the time. The motion sensors were storing data for each workstation separately, so each workstation file was processed separately and placed in a single room for occupancy's file.

\section{Analytical}

The rest of the research is analytical comparison performing simulations with the dynamic energy simulation software DesignBuilder version 6.1.2.005. The analysed (observed) building model was created and simulated for 3 different cases of occupancy schedule:

1. DesignBuilder - default open space occupancy schedule proposed by DesignBuilder software database;

2. EN 16798-1:2019 Energy performance of buildings (Lietuvos standartizacijos departamentas, 2019). Ventilation for buildings. Input parameters for indoor environment design, thermal environment, lighting and acoustics for the design and assessment of the energy performance of buildings. Module M1-6, which provides open office occupancy schedules for building' energy performance evaluation.

3. Actual - measured and statistically generated occupation schedules of an open office.

Figure 2 shows a created DesignBuilder 3D geometry model of the building under the study. Also, the detailed HVAC system model of the building is created in the DesignBuilder and is presented in Figure 3.
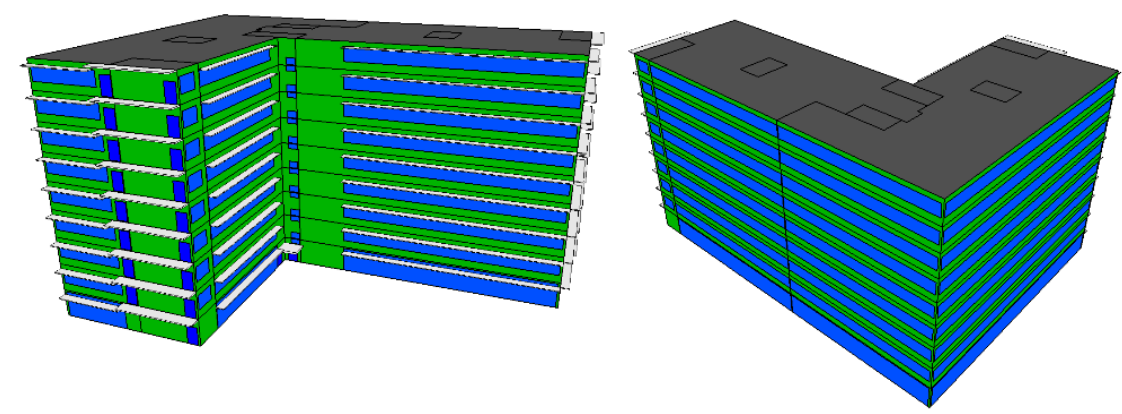

Figure 2. Building 3 D model in DesignBuilder

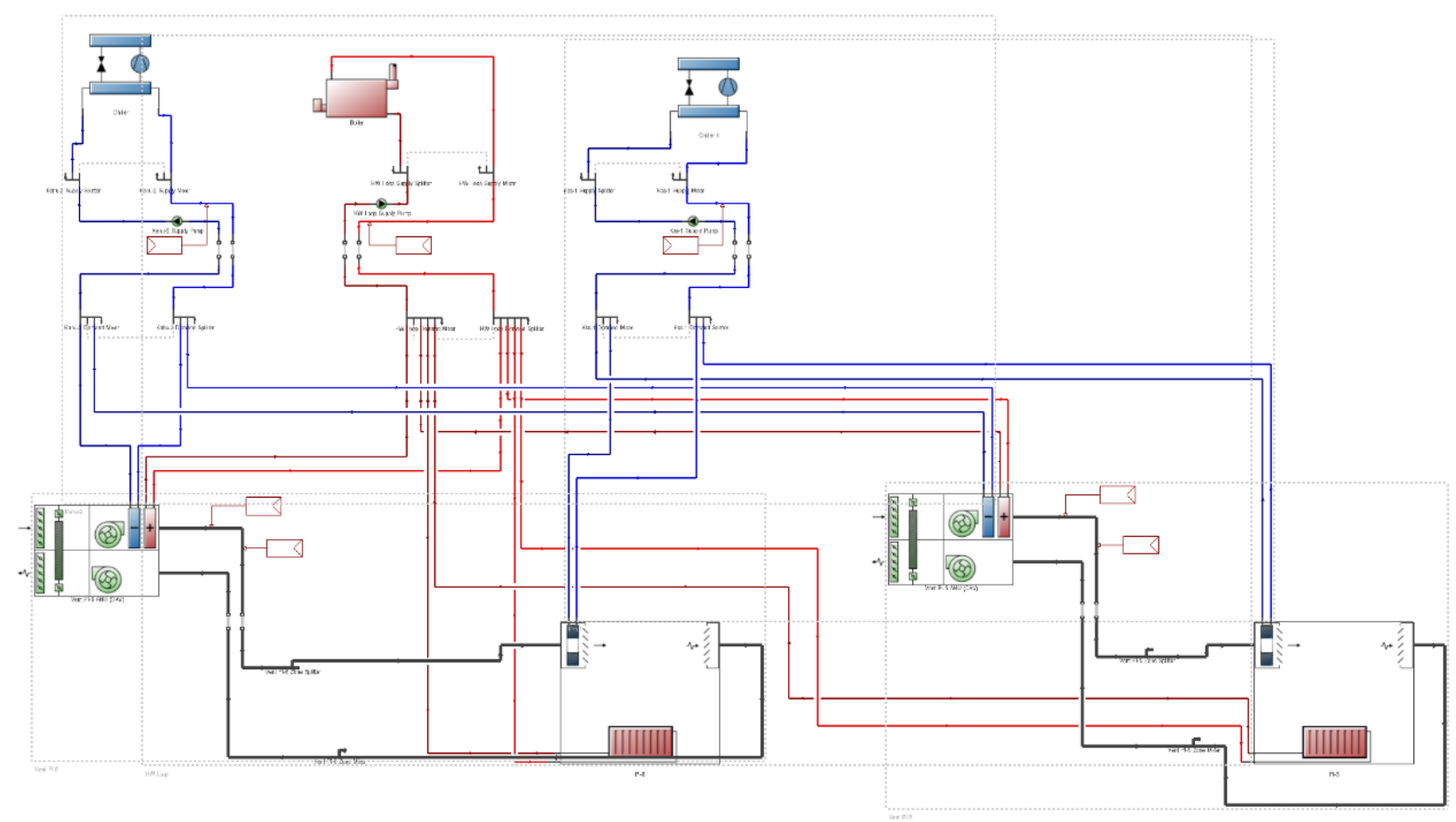

Figure 3. Detailed model HVAC systems in DesignBuilder 
Figure 3 shows two AHU's that condition the outdoor air and supply it to the building premises. The air flow of AHU shown on the left side is $20680 \mathrm{~m}^{3} / \mathrm{h}$ and on the right $-20218 \mathrm{~m}^{3} / \mathrm{h}$. During the summer, air is cooled in AHU's cooling section, which is connected to the chiller (left side) with a capacity of $864 \mathrm{~kW}$. Active chilled beams supply chilled air to premises and the additional cooling is performed by the chiller with a capacity of $490 \mathrm{~kW}$ (right side). During the heating season radiators maintain indoor temperature with the heat supplied from the central power plant. The total heating capacity is $850 \mathrm{~kW}$.

\section{Results}

Three different cases - DesignBuilder default, standard EN 16798-1 and actual measured were simulated and compared to investigate the influence of occupants schedules assumptions on energy consumption in the open office. Figure 4 presents comparison of occupancy profiles used in simulations. Actual occupancy is determined by the arithmetic data of the specific hour over the measured period and the maximum of occupation.

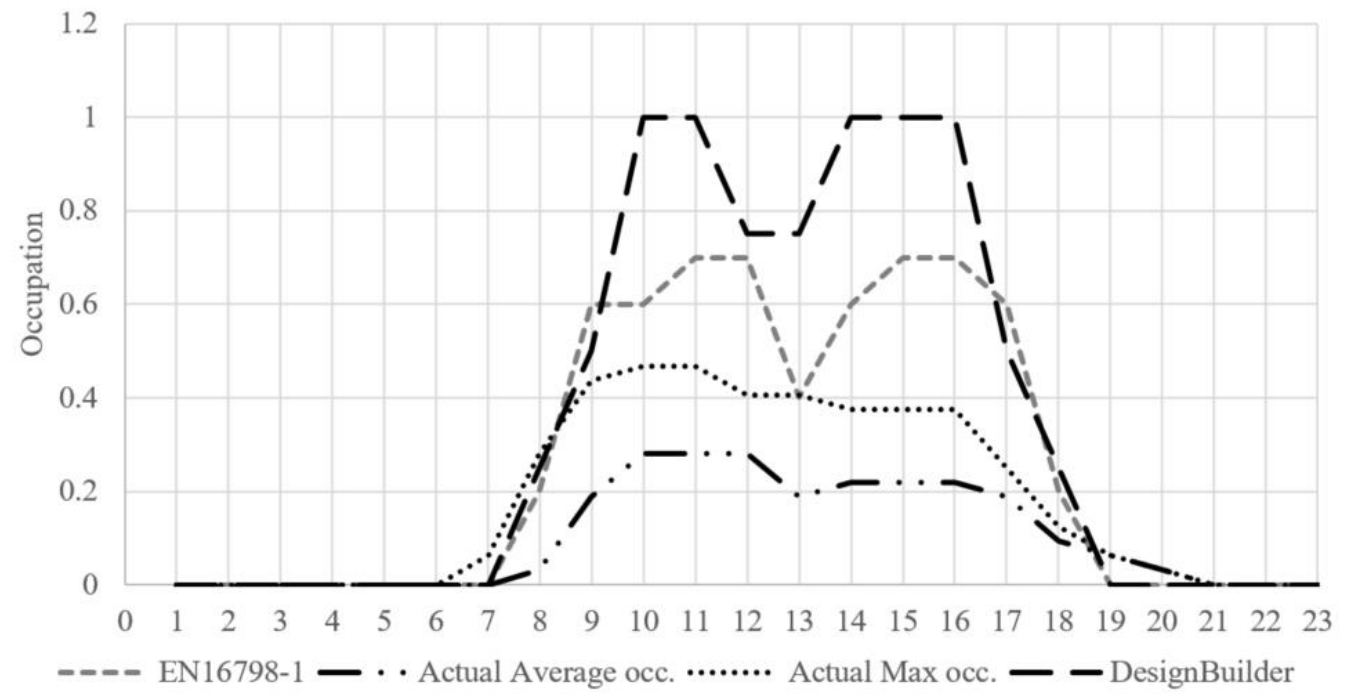

Figure 4. Daily schedules of human occupancy schedules

The actual occupancy was significantly lower than the one given in normative document EN 16798-1 or DesignBuilder as default schedule. Actual occupancy trend is similar to the other cases - showing peaks at similar periods of the day, also showing that during the lunch time occupancy decreases, but fluctuations during the day for the actual case are low compared to the other cases. This can be explained by very low actual occupancy and the occupants are very mobile, they do not have their own workstations as they arrive at the office just to perform certain tasks and then leave. This is also an indication for an employer, that such style of mobile work does not need so much space to rent as this is the waste of energy and financial resources.

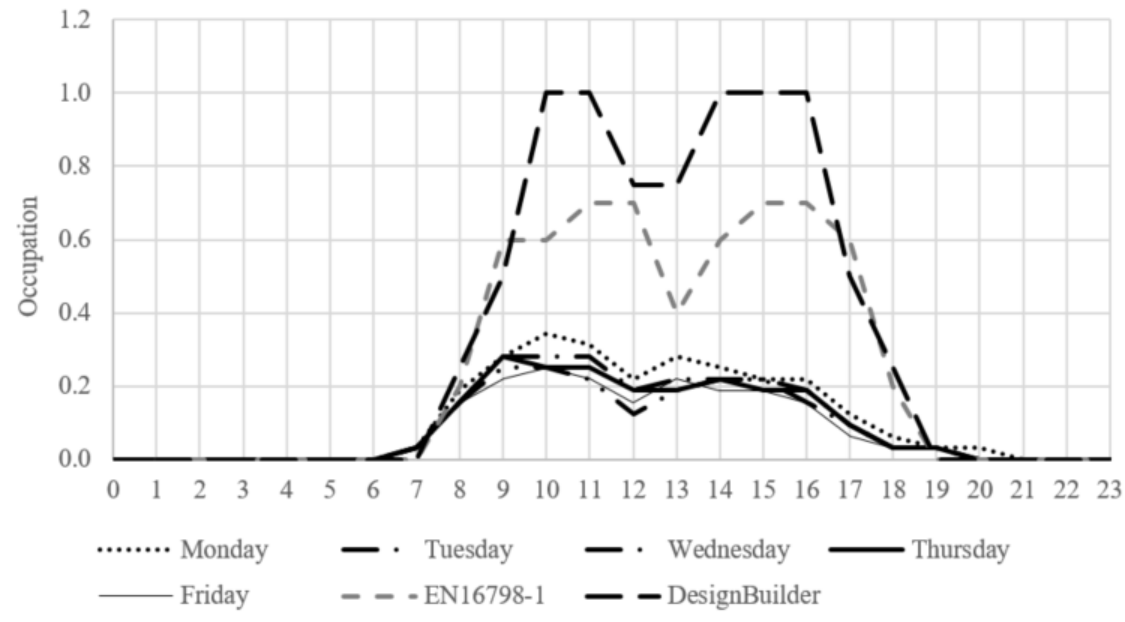

Figure 5. Human occupancy schedules daily 
Figure 5 shows the actual hourly average of occupation on each working day. The graph shows that all working days are similar.

Figures 6, 7 and 8 show the results obtained by simulating a building with three different occupation schedules. The results are shown in terms of final energy - electrical and thermal. Figure 6 shows annual thermal energy demand of the occupied spaces to maintain the default temperature and the total amount of electrical energy due to the cooling of the equipment and the room. The results show that energy demand differs for different types of occupants' schedules. The difference between heating energy demand for DesignBuilder and standard occupancy profile cases is $7 \mathrm{kWh} / \mathrm{m}^{2}$ (about 19\%), between standard and actual occupancy $-9 \mathrm{kWh} / \mathrm{m}^{2}$ (about 21\%). It can be seen that the smaller the number of occupants in the room, the greater the demand for heating to maintain the temperature. This is explained by smaller internal gains from occupants. Differences in cooling energy demand are more significant: there is a difference of $46 \mathrm{kWh} / \mathrm{m}^{2}$ (about $46 \%$ ) between DesignBuilder and standard profile cases and $4 \mathrm{kWh} / \mathrm{m}^{2}$ (about 20\%) between standard and actual occupancy cases. Electricity demand difference is opposite to thermal energy. The higher the occupancy, the more electricity is required, which is logical because occupants and their activities produce more undesired heat gains during the cooling season.

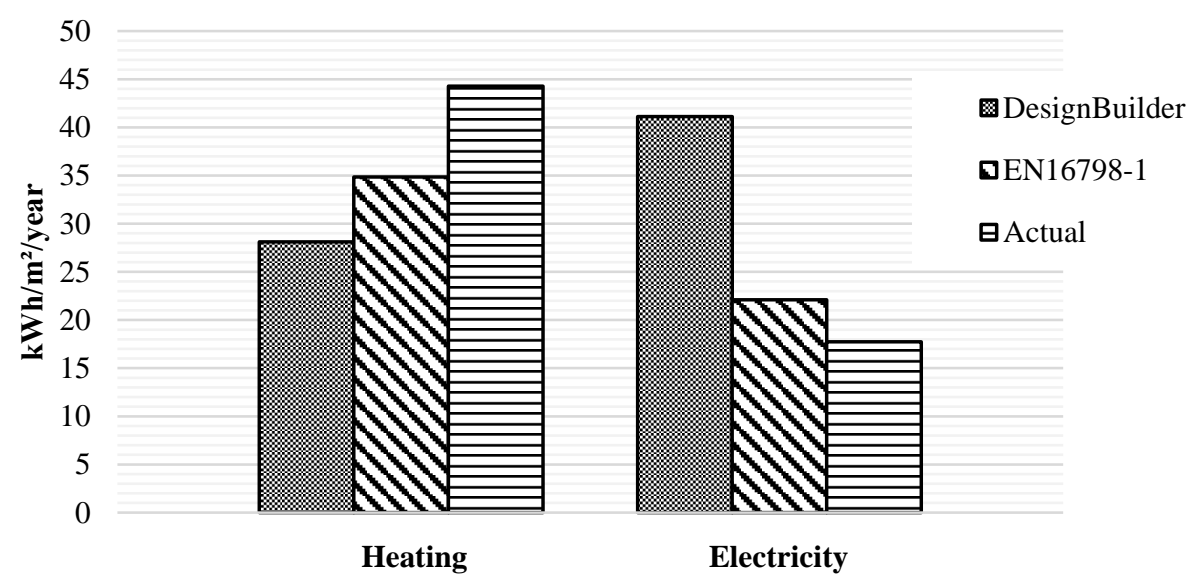

Figure 6. Heating and cooling (electricity) final energy demand of occupied premises

Figure 7 shows the electricity consumption broken down by users: computers and other office equipment, cooling, lighting. The lower the occupancy of the premises, the lower the electricity consumption for all appliances, cooling and lighting systems.

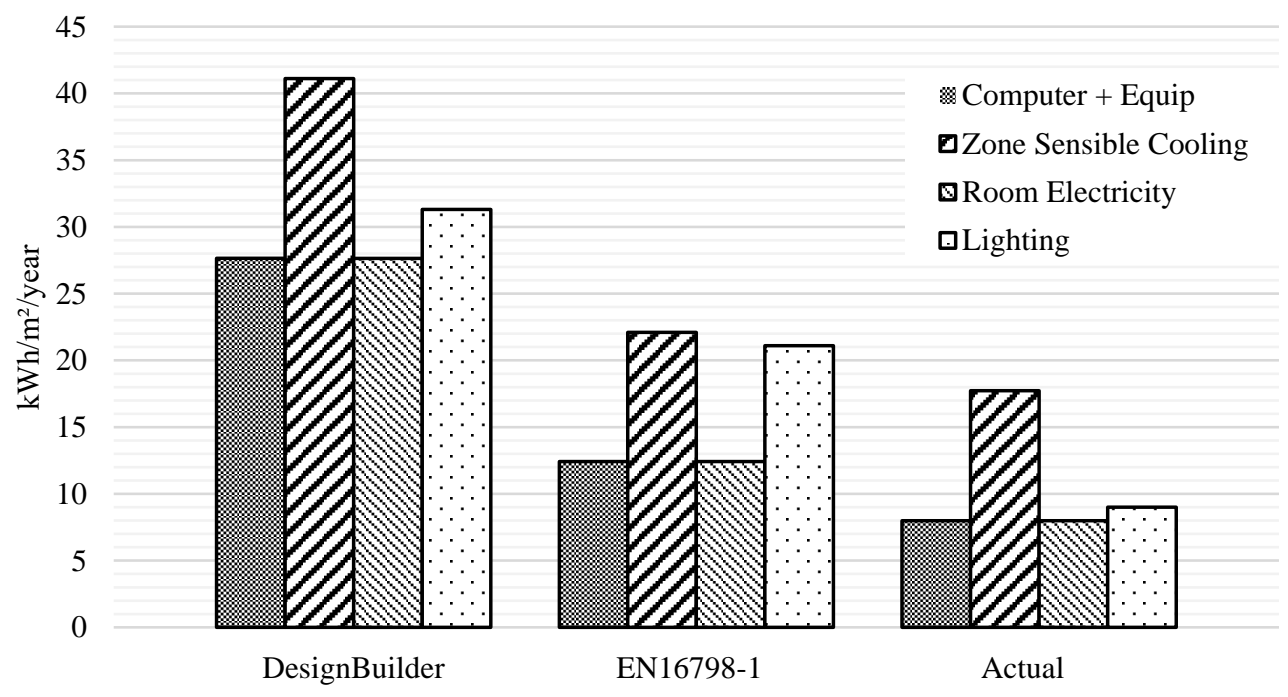

Figure 7. Electricity demand based on the operation of engineering systems 
Occupants emit thermal energy while indoors, and its effect can be seen in Figure 8. We can see that the heat generated by the DesignBuilder due to the presence of the users in the room is $13 \mathrm{kWh} / \mathrm{m}^{2}$ or about $50 \%$ higher than the occupancy of the standard document users and the standard heat output is $4.4 \mathrm{kWh} / \mathrm{m}^{2}$ or about $33 \%$ more than the actual heat released by the occupants. As a result, people's influence on the heating system is significant, leading to an increase in heat demand as occupant employment declines. Annual heating demand for standard occupancy is higher by $6.7 \mathrm{kWh} / \mathrm{m}^{2}$ (about 24\%) than DesignBuilder, and occupant influence for actual occupancy is higher by $9.4 \mathrm{kWh} \mathrm{m}^{2}$ (about $27 \%$ ) than standard occupancy.

Therefore, as we can see from the results that the actual occupancy of the premises and its influence on the energy consumption of the building differs from the occupancy schedules according to the DesignBuilder program and the normative document EN 16798-1. This mismatch is called - Performance Gap (Galvin, 2014).

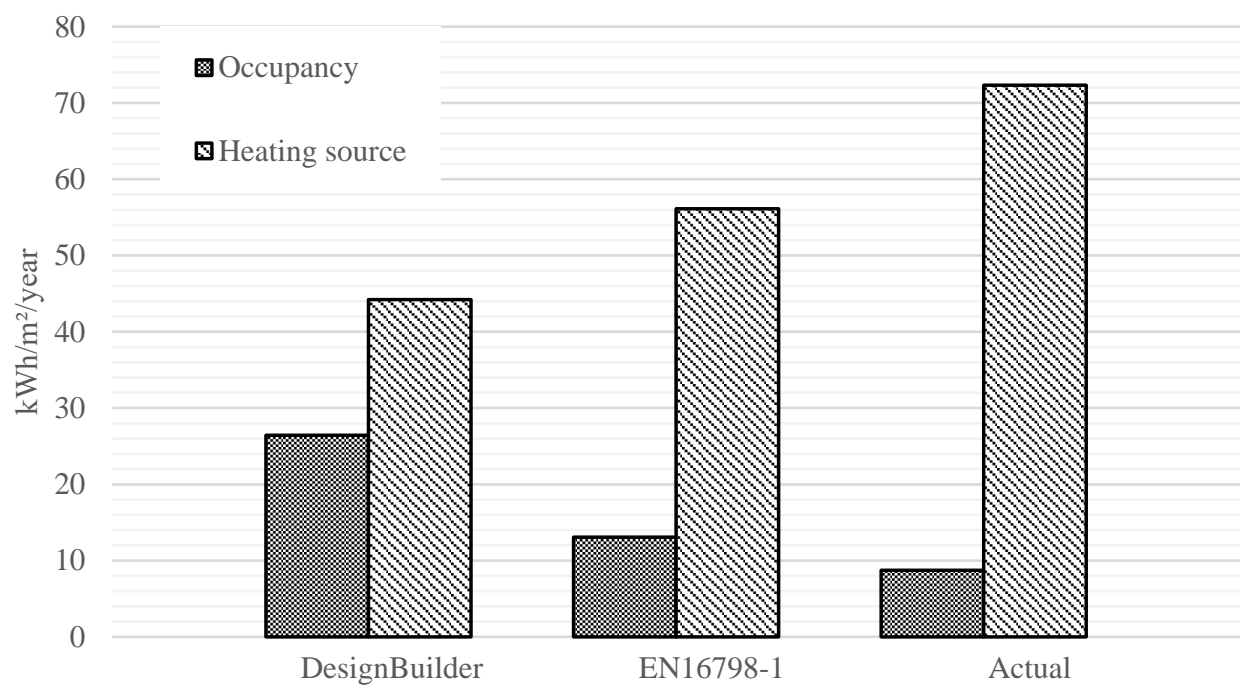

Figure 8. Consumption of thermal energy by operation of engineering systems

The primary energy consumption of a building due to human occupancy can be seen in Figure 9 . We can see that DesignBuilder is higher by $111 \mathrm{kWh} / \mathrm{m}^{2}(32 \%)$ than the standard case, and $-152 \mathrm{kWh} / \mathrm{m}^{2}(44 \%)$ than the actual one. Primary energy conversion factors uses are assumed according to Lithuanian norm STR 2.01.02:2016 (Lietuvos Respublikos aplinkos ministerija, 2016): the average of various electricity production methods -2.8 ; natural gas -1.1 . for different energy production fuel balances. Especially for electricity, these differences may strongly vary.

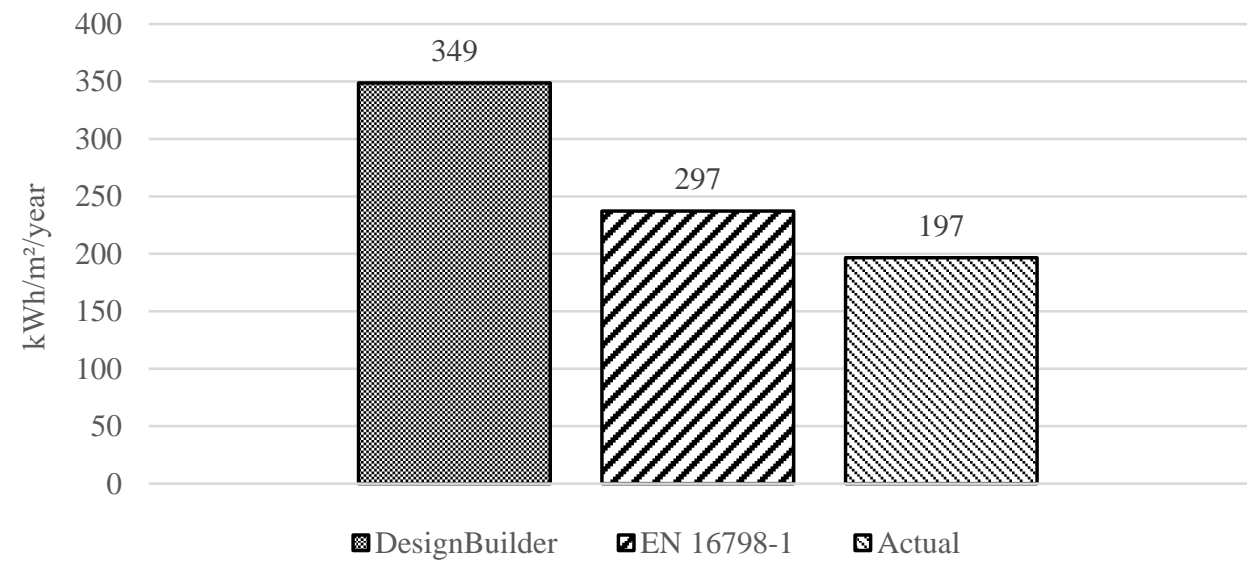

Figure 9. Total primary energy consumption of a building 


\section{Conclusions}

1. The experimentally defined occupancy schedules in an open-ended office have shown that actual occupancy is less than about 3.5 times than the difference compared to the default DesignBuilder's schedules and 2.7 times less compared to the ones given in norms EN 16798-1.

2. Simulation with the DesignBuilder of three cases with different occupancy schedules has shown that compared to actual occupancy case, heating energy demand with standard occupancy profile is $21 \%$ higher, while with default DesignBuilder schedules - 36\% higher. Accordingly, comparing the electricity energy demand with standard occupancy profile it is $20 \%$ lower and with default DesignBuilder profiles case $-57 \%$ lower.

3. When analysing differences in primary energy demand, for the case with standard (EN 16798-1) profiles it is $18 \%$ and for default DesignBuilder profiles - $43.6 \%$ higher compared to the case with actual occupancy profiles.

4. For open office building, which has already been discussed in other literature sources, and which has been also proved for other types of buildings, the passive influence (presence) of occupants on the accuracy of prediction of building's energy demand is significant to cause mismatch of predicted and actual energy consumption, also called Performance Gap.

\section{References}

Delzendeha, E., Wua, S., Leea, A., \& Zhou, Y. (2017). The impact of occupants' behaviours on building energy analysis: A research review. Renewable and Sustainable Energy Reviews 80, 1061-1071. https://doi.org/10.1016/j.rser.2017.05.264

Diraco, G., Leone, A., \& Siciliano, P. (2015). People occupancy detection and profiling with 3D depth sensors for building energy management. Energy and Buildings, 92, 246-266. https://doi.org/10.1016/j.enbuild.2015.01.043

Galvin, R. (2014). Making the 'rebound effect' more useful for performance evaluation of thermal retrofits of existing homes: Defining the 'energy savings deficit' and the 'energy performance gap'. Energy and Buildings, 69, $515-524$. https://doi.org/10.1016/j.enbuild.2013.11.004

Hong, T., Taylor-Lange, S., D’Oca, S., Yan, D., \& Corgnati, S. (2016). Advances in research and applications of energy-related occupant behavior in buildings. Energy and Buildings, 116, 694-702. https://doi.org/10.1016/j.enbuild.2015.11.052

Lietuvos Respublikos aplinkos ministerija. (2016). Pastatu energetinio naudingumo projektavimas ir sertifikavimas, D1-754 (STR 2.01.02:2016). Statybos techninis reglamentas.

Lietuvos standartizacijos departamentas. (2019). Energy performance of buildings - Ventilation for buildings - Part 1: Indoor environmental input parameters for design an assessment of energy performance of buildings addressing indoor air quality, thermal environment, lighting and acoustics - Module M1-6 (LST EN 16798-1:2019).

Pedersen, T. H., Nielsen, K. U., \& Petersen, S. (2017). Method for room occupancy detection based on trajectory of indoor climate sensor data. Building and Environment, 115, 147-156. https://doi.org/10.1016/j.buildenv.2017.01.023

Yan, D., Hong, T., Dong, D., Mahdavi, A., Oca, S., Gaetani, I., \& Feng, X. (2017). Definition and simulation of occupant behavoir in buildings. Energy and Buildings, 156, 258-270. https://doi.org/10.1016/j.enbuild.2017.09.084 